\title{
An Unmanned Aerial Vehicle for Rangeland Photography
}

\author{
Perry J. Hardin ${ }^{1}$ and Mark W. Jackson ${ }^{2}$ \\ Authors are ${ }^{1}$ Associate Professor and ${ }^{2}$ Assistant Professor, Department of Geography, \\ Brigham Young University, Provo, UT 84602.
}

\begin{abstract}
Because of its perceived impracticality and expense, aerial photography from unmanned aerial vehicles (UAVs) remains virtually unused as a rangeland management tool. This underuse suggested 2 objectives. The first was to develop a UAV from off-the-shelf components that could acquire low-altitude large-scale photography for rangeland documentation. The second was to assess the UAV flight characteristics. A remotely controlled UAV suitable for 35-mm photography was built in 56 hours at a cost of $\$ 1480$. In a 2-year test period, the UAV successfully completed $100+$ sorties at elevations ranging from $10 \mathrm{~m}$ to $1000 \mathrm{~m}$ above ground. The average distance required for takeoff is $18.2 \mathrm{~m}$ whereas landing requires an average of $22.5 \mathrm{~m}$. Average UAV airspeed at takeoff is about $11.4 \mathrm{~m} \cdot \mathrm{s}^{-1}$. Typical cruise speed during photograph acquisition is $13.8 \mathrm{~m} \cdot \mathrm{s}^{-1}$, resulting in $6.9 \mathrm{~mm}$ of blur from forward-image motion. The UAV is an inexpensive tool for monitoring rangeland condition from an aerial perspective. It is currently being used to map squarrose knapweed (Centaurea virgata Lam. ssp. squarrosa Gugl.) density at several rangeland sites in Utah.
\end{abstract}

\section{Resumen}

Debido a que se percibe que la fotografía aérea obtenida de vehículos aéreos no tripulados (UVAs) es cara e impráctica, permanece virtualmente sin uso como una herramienta de manejo de los pastizales. Esta subutilización sugirió dos objetivos de investigación: El primero fue desarrollar a UAV a partir de componentes descontinuados el cual pudiera obtener fotografías a baja altitud y gran escala para documentación de los pastizales, el segundo fue evaluar las características de vuelo de UAV. Un UAV de control remoto apropiado para una cámara fotográfica de $35 \mathrm{~mm}$ se construyó en 56 horas a un costo de \$1 480 . En un periodo de prueba de 2 años, el UAV completó exitosamente 100 vuelos a elevaciones entre 10 y 1000 m arriba de la superficie del suelo. La distancia promedio requerida para despegar fue de $18.2 \mathrm{~m}$ mientras que el aterrizaje requiere en promedio $22.5 \mathrm{~m}$. La velocidad promedio del UAV durante el despegue fue aproximadamente $11.4 \mathrm{~m} \cdot \mathrm{s}^{-1}$. La velocidad promedio de crucero durante la toma de las fotografías es de $13.8 \mathrm{~m} \cdot \mathrm{s}^{-1}$, resultando en $6.9 \mathrm{~m}$ de imprecisión hacia delante del movimiento de la imagen. El UAV es una herramienta barata para el monitoreo de la condición del pastizal a partir de perspectivas de fotografías aéreas. Actualmente esta siendo utilizado para mapear la densidad de "Squarrose knapweed" (Centaurea virgata Lam. ssp. squarrosa Gugl.) en varios sitios de pastizal de Utah.

Key Words: aerial photography

\section{INTRODUCTION}

For many rangeland managers, the high cost of aerial photography can preclude its use. Multiagency cooperation can mitigate this expense, but conflicting application requirements can result in photography suboptimal for some purposes. Even when contracted specifically for resource management, the 1:20 000-scale to 1:10 000-scale photography used for periodic resource inventory remains too small for rangeland management tasks needing more intricate detail.

Funded by National Aeronautics and Space Administration (NASA), the exploratory use of aerial photography at larger scales (1:600 to 1:6 000) for rangeland science blossomed briefly in the 1960s when researchers determined that rangeland monitoring, inventory, and sampling could be enhanced by the use of such large-scale photographs (Carneggie and Reppert 1971). With the advent of digital cameras in the

Correspondence: Perry J. Hardin, Department of Geography, Brigham Young University, 690 SWKT, Provo, UT 84602. Email: perry_hardin@byu.edu

Manuscript received 12 December 2004; manuscript accepted 14 April 2005. 1990s, large-scale air photography for rangeland management again flourished briefly under the marquee "small-format photography" (Everitt et al. 1997). In 2005, this small-format technology remains expensive, requiring both pilot and conventional aircraft, respectively, to operate and carry the system.

The use of radio-controlled aircraft to acquire large-scale photography for ecological studies is not new. Nyquist (1997) successfully used a Senior Telemaster airframe with both $35-\mathrm{mm}$ and video cameras to monitor hazardous sites at Oak Ridge National Laboratory. In controlled experiments, Quilter and Anderson (2001) demonstrated the use of small UAVs for monitoring rangeland biomass. More recently, Hunt et al. (2003) mounted a 35-mm camera on a radio-controlled aircraft to photographically evaluate the impact of nitrogen fertilizer on corn growth.

The UAV presented herein extends these past successes. It represents a significant decrease in cost compared with the Nyquist UAV ( $\$ 1500$ vs. $\$ 5000$ ) as well as a significant decrease in building time compared with the Quilter and Anderson drone (56 hours vs. $\approx 200$ hours [M. Quilter, personal communication, September 2003]). Flying difficulty is also lessened by including a flight-stabilization system aboard 
the UAV, obviating the need for the semiprofessional UAV pilot used in both the Nyquist and the Quilter and Anderson experiments (V.J. Anderson, personal communication, September 2003). The use of on-board global positioning system (GPS) flight-path tracking, not used in the previous research, represents an improvement in the ability to accurately geolocate UAV rangeland photographs.

\section{OBJECTIVES}

The 2 objectives of this research were 1) to design and build a small, radio-controlled UAV from inexpensive, off-the-shelf components that could be used for imaging rangelands at low altitudes; and 2) to determine its feasibility as a rangeland research tool by assessing its flight characteristics. This article describes the UAV subsystems in detail and describes the UAV flight characteristics under controlled test conditions.

\section{UAV SYSTEM COMPONENTS}

The UAV can be treated as 4 subsystems: the airframe, the engine, the avionics, and the camera. A detailed table of aircraft system components is available from the authors.

\section{Airframe}

Because of constraints, such as limited building time and limited woodworking skills, a prebuilt UAV airframe was preferable to a kit. Slow-flight capability was essential; blur from camera forward-image motion is cited as a major cause of poor vertical air photography (Walker and De Vore 1995). Aircraft stability and maneuverability in winds typical of the Great Plains between May and October $\left(\approx 6 \mathrm{~m} \cdot \mathrm{s}^{-1}\right)$ was also required. Because aircraft roll and pitch would introduce geometric distortion into vertical air photographs, aircraft disposition to straight, level flight was another necessity. The fuselage width had to accommodate a $35-\mathrm{mm}$, single-lens reflex (SLR) camera. Finally, the wings needed to provide sufficient lift to carry the estimated camera and electronics payload weight of $1.0 \mathrm{~kg}$ without degrading the flight characteristics cited above.

After studying many alternatives, the prebuilt UAV airframe chosen was the Kadet Senior (Sig Manufacturing Company, Montezuma, IA). This aircraft maintains a notable reputation as a stable aircraft designed for novice fliers. Its slow flight and large lift capacity are a result of its large wing area $\left(7613 \mathrm{~cm}^{2}\right)$, high-wing configuration, flat-bottom airfoil, and light weight $(2.94 \mathrm{~kg})$. Wing dihedral is adequate to add lateral stability to the aircraft but moderate enough to minimize kiting in windy situations. An oversized horizontal stabilizer and fin lend longitudinal stability and directional stability, respectively. The width of the fuselage $(11.5 \mathrm{~cm})$ is sufficient to carry a variety of SLR cameras. The aircraft is also transportable in the back of a small pickup truck, and two UAVs can easily fit in a $1.2 \mathrm{~m} \times$ $2.5 \mathrm{~m}$ utility trailer.

\section{Engine}

Because engine performance is paramount in all aircraft, 6 engines were tested in 4 UAV designs for a period of 2 years over rangeland sites in the Mountain West and Great Plains.
As a result of this testing, the O.S. model .61 FX 2-stroke (O.S. Engines MFG. Co Ltd, Osaka, Japan) became the standard engine for the UAV. The O.S. model .61 FX engine operates on a fuel mixture of methanol, nitromethane, castor oil, and synthetic oils. To minimize camera jitter and airframe fatigue, commercial vibration-dampening mounts were used for attaching the engine to the airframe. Precision-balanced wooden propellers further reduced vibration. The use of wooden propellers (rather than rigid plastic alternatives) also minimized the risk of serious propeller-induced finger injury.

\section{Avionics}

To increase the UAV stability, a flight-stabilization system (model FS8; FMA Direct Inc, Frederick, MD) was used on all photographic flights. Using 4 infrared sensors, looking forward, aft, left, and right, the flight stabilization system issues correction commands to the ailerons and elevator to keep the aircraft fuselage and wings level with their respective horizons. In this research, the flight stabilization system was engaged in all phases of the UAV flight except takeoff. When the flight stabilization system was enabled, the UAV still responded to normal flight commands. However, when the aileron and elevator controls were left in neutral during photo acquisition, the flight stabilization system assumed control and maintained the aircraft in level flight. The system ensured that the photographs were acquired vertically (or nearly so) by compensating for tilt and roll while the pilot 1) maintained the correct aircraft heading with the rudder, and 2) triggered the camera shutter. The flight stabilization system also reduced crash risk. When faced with a problem when the UAV was airborne (e.g., aircraft obscured by the sun), the pilot could release the transmitter controls, and the flight stabilization system would maintain straight-and-level flight until manual control could be reasserted. In 2 years of field testing, which included over 30 hours of flight time, no UAV crashed with the flight stabilization system properly engaged.

As noted by Hunt et al. (2003), maintaining uniform aircraft flight altitude during photograph acquisition is a difficult challenge when flying small UAVs. This problem was solved by installing a barometric pressure-control device (Model PDC 20, UNAV LLC, Marysville, WA) commonly used in radiocontrolled aircraft. When engaged, the device would maintain the UAV altitude by automatically adjusting the elevator angle.

An aircraft receiver and handheld transmitter form the control link between the pilot on the ground and the UAV aloft. Different channels provide for control of different aircraft functions. For this research, a 7-channel transmitter and matching aircraft receiver were generally used. Four channels operated the aircraft throttle, rudder, ailerons, and elevator, respectively. A fifth channel was used to trigger the camera shutter via an electronic switch (Model EA02, EMS Jomar Industries, Yorba Linda, CA) aboard the aircraft. The sixth radio channel was used to enable, disable, and adjust the sensitivity of the flight-stabilization system while in flight. The seventh channel was used to engage the altitude-hold device.

The GPS receiver accompanying the aircraft continually logged its flight path at 1-second intervals. A Garmin (Olathe, KS) Geko 201 GPS receiver was selected because of its light weight $(88 \mathrm{~g})$ and small size $(99 \times 48 \times 24 \mathrm{~mm})$. Its Wide Area 
Augmentation Service capability provided geolocation accuracy of about $3 \mathrm{~m} \mathrm{(} 2 \sigma$ root mean square error). Velcro was used to secure the receiver to the wing saddle during flight. Upon landing, the GPS ground track was downloaded and analyzed using GPSU 4.15.1 software (GPS Utility Ltd, Hampshire, UK). This analysis yielded aircraft 3-D position and velocity while the photographs were being acquired. After the photographs were developed, locations of interest were easily found by following the flight paths on the ground with the GPS receiver and photos in-hand.

\section{Camera}

Practical 35-mm camera recommendations for low-altitude photography are reported by Walker and De Vore (1995). For this research a Pentax Imaging (Golden, CO) ZX-M 35-mm SLR with $50-\mathrm{mm}$ lens was selected as the primary payload.

\section{AIRCRAFT MODIFICATIONS}

Most of the modifications were done in the 3-cockpit compartments of the airframe. Figure $1 \mathrm{~A}$ shows the camera in the forward compartment aligned over the aircraft center of gravity. To minimize vibration, the camera rests on several sandwiched layers of foam rubber sufficiently thick to keep the camera lens from protruding through the fuselage bottom. The camera is held in place by a security plate; a sheet of 3-mm-thick aircraft plywood spans the extent of the forward cockpit with an intervening layer of foam between it and the camera. The plate is screwed tightly in-place with a $4-40 \times$ three-quarter inch, hex-head screw at each corner. The barometric pressure control device (not shown) is secured atop the security plate with Velcro. The aft portion of the center cockpit compartment (Fig. 1A) houses the rudder, elevator, and throttle servos whereas the forward section of the compartment is reserved for future instrumentation (e.g., a video-targeting camera).

The design of the aft cockpit (Fig. 1B) places the flightstabilization system (1) and the lithium-polymer battery (2) within easy reach. The battery is secured to the radio-mounting table with Velcro. The flight-stabilization system rides on a piece of foam rubber glued to the radio-mounting table, isolating the flight-stabilization system from airframe vibration. A slot in the table passes the flight-stabilization system cable to a corresponding slot in the bottom of the fuselage. The flightstabilization system cable terminates at the infrared horizon sensor attached to the bottom of the fuselage (not shown).

A thin plywood access panel secured with 2-56 hardware replaces the aircraft covering for the first 2 frame sections immediately aft of the rear cockpit. As shown in Figure 1B, the aircraft switches and indicators (3-6) are mounted on (or beneath) the access panel. All these controls are wired according to manufacturer instructions.

\section{FLIGHT TEST RESULTS}

Two years of flight testing, consisting of $100+$ flights, was conducted at rangeland sites in Utah, Colorado, New Mexico, and Texas. The UAV was flown at altitudes ranging from $16 \mathrm{~m}$ above mean sea level (MSL) to $2070 \mathrm{~m} \mathrm{MSL}$ and in winds exceeding $12 \mathrm{~m} \cdot \mathrm{s}^{-1}$.

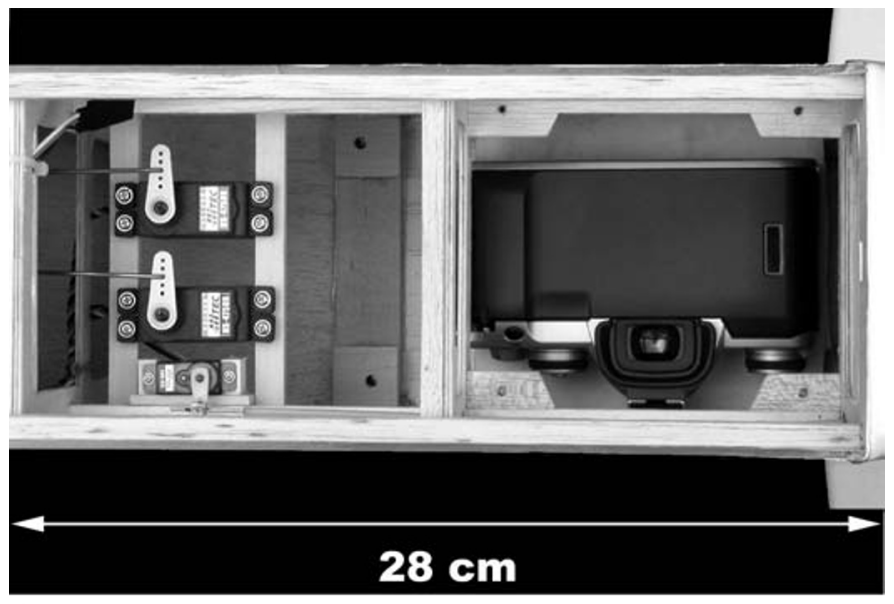

A

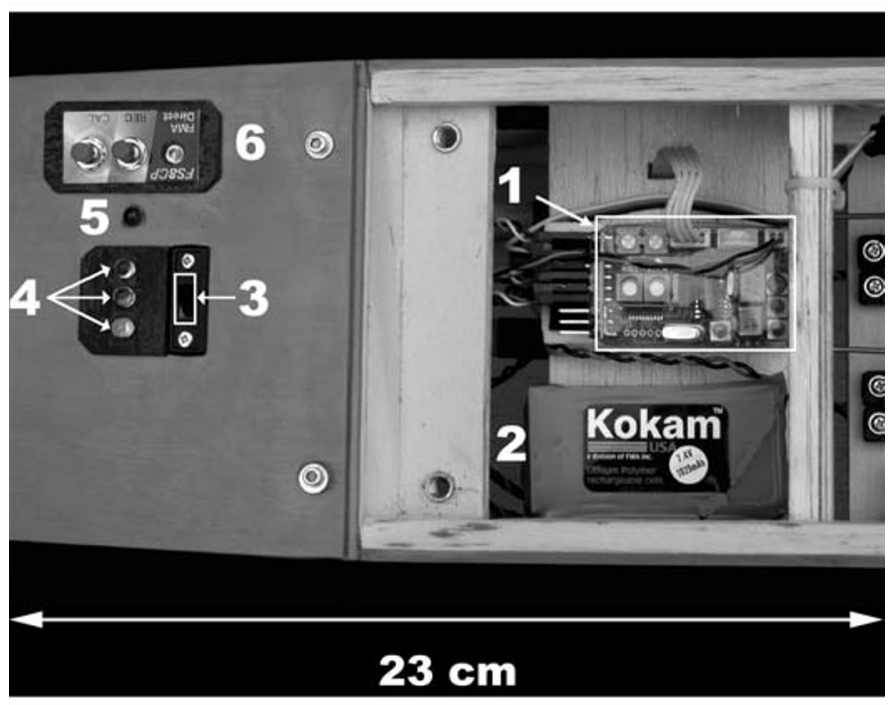

B

Figure 1. The cockpit areas after modification. A, The forward and middle cockpit areas were designed to hold the camera and control servos. The 4 holes for mounting the camera security plate are visible in the 4 corners of the forward cockpit; 4-40 blind nuts back the holes. B, The aft cockpit area houses the flight stabilization system (1), the battery (2), aircraft main power switch (3), battery-level indicator lights (4), camera trigger indicator (5), and fight stabilization system calibration switches (6).

Insurance liability required that the flying UAV remain within unaided visual site. This limited the visual flight radius to about $1000 \mathrm{~m}$ and provided for belt transect flights of $2000 \mathrm{~m}$ length when piloted from the transect center. The maximum flying height above ground level (AGL) was also limited by aircraft visibility. In 2 years of flight, altitudes exceeding $1000 \mathrm{~m}$ AGL were routinely achieved without risk of losing visual contact with the UAV.

Minimum landing and takeoff distance requirements were empirically determined. This testing was conducted at the Pony Express Marker field site in Utah County, Utah (lat $40^{\circ} 13^{\prime} 19^{\prime \prime} \mathrm{N}$, long $\left.112^{\circ} 17^{\prime} 33^{\prime \prime} \mathrm{W}, 1537 \mathrm{~m} \mathrm{MSL}\right)$. Takeoff distance was defined as the distance from dead start to liftoff from ground. Landing distance was defined as the distance from first touchdown to full stop. For takeoffs, the average distance 


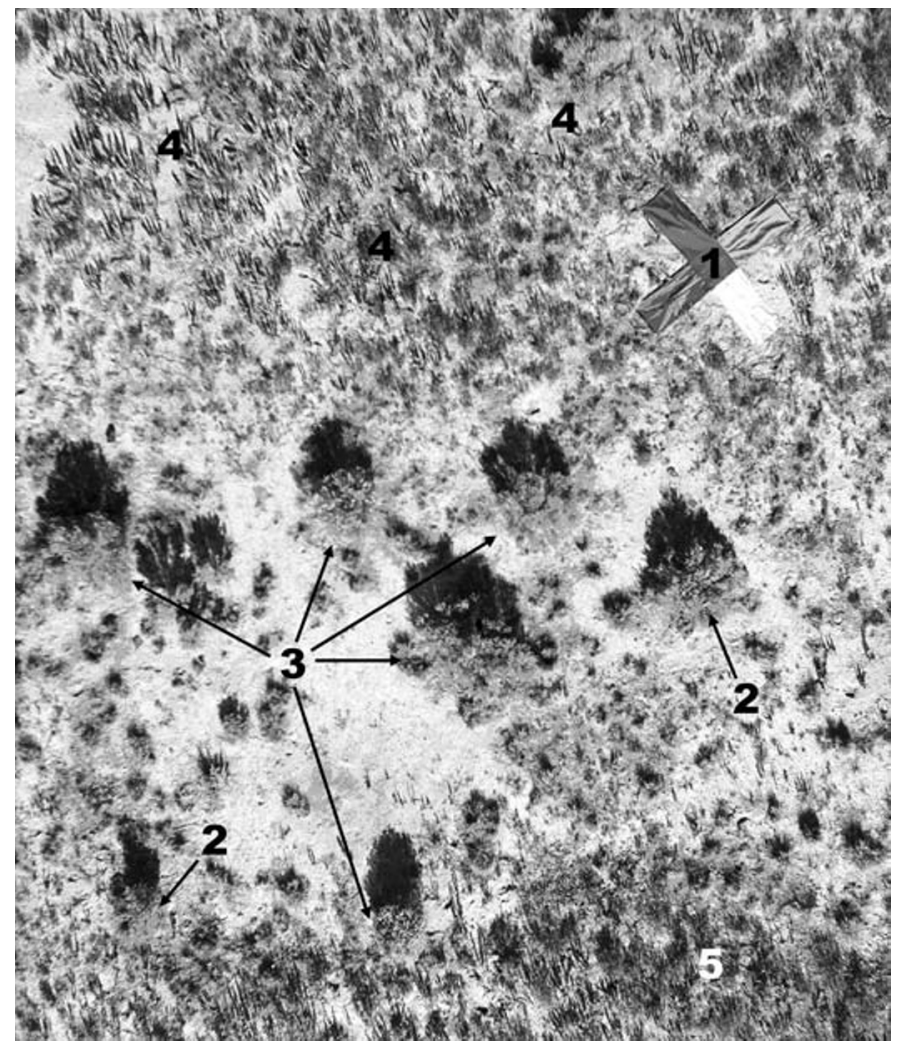

Figure 2. Average unmanned aerial vehicle (UAV) photographic quality represented by a photograph taken in Rush Valley, Utah. Color panels (1), big sagebrush (2), greasewood (3), halogeton (Halogeton glomeratus [Stephen ex Bieb.] C.A. Mey) area (4), and a halogeton and Russian thistle (Salsola iberica Sennen) mix area (5) are all discernable. Significant detail has been lost in the conversion from the color original to this monochrome rendition. For example, in the original, the greasewood and big sagebrush appear bright green and sage green, respectively, making them easy to visually discriminate. Each color panel wing (1) is $1-\mathrm{m}$ long.

required was $18.2 \mathrm{~m}(s=2.8, n=15)$. The average recorded takeoff speed (recorded by the GPS receiver) was $11.4 \mathrm{~m} \cdot \mathrm{s}^{-1}$ $(s=1.0, n=18)$. Landing distance was much more variable $(\bar{x}=22.5 \mathrm{~m}, s=12.4, n=16)$ and largely depended on pilot ability to land the aircraft without bouncing it. All takeoff and landing tests were done under windless conditions. A significant decrease in these speeds and distances was noted when flying into a headwind.

The blur of air photographs from forward motion can be defeated by slow aircraft speeds and fast camera shutter speeds (Walker and De Vore 1995). To calculate the UAV forwardimage motion, 85 passes were made over photographic targets at the slowest possible speed while maintaining steerage and altitude. During these 85 passes, the aircraft flew at an average ground speed of $13.8 \mathrm{~m} \cdot \mathrm{s}^{-1}(s=2.4, n=85)$. Given the fastest shutter speed of $1 / 2000 \mathrm{~s}$ available with the SLR camera, the average forward-image motion during photograph acquisition was thus $6.9 \mathrm{~mm}$. Like distances for landing and takeoff, this value would decrease if photographs were acquired while flying into a headwind.

Figure 2 demonstrates the average photographic quality obtained by the aircraft in tests conducted during October 2003 in southern Rush Valley, Utah (lat $40^{\circ} 12^{\prime} 47^{\prime \prime} \mathrm{N}$, long $\left.112^{\circ} 15^{\prime} 11^{\prime \prime} \mathrm{W}, 1542 \mathrm{~m} \mathrm{MSL}\right)$. The photograph was taken from an elevation of $35 \mathrm{~m}$ AGL. Even in this reduced-resolution, monochrome rendition of a color-photograph original, individual big sagebrush (Artemisia tridentata Nutt.) and greasewood (Sarcobatus vermiculatus [Hook.] Torr.) plants are visible, as well as communities of halogeton (Halogeton glomeratus [Stephen ex Bieb.] C.A. Mey) and Russian thistle (Salsola iberica Sennen).

\section{AN APPLICATION EXAMPLE}

The long-term agenda for this UAV technology is focused on identifying rangeland applications that can benefit from UAV imagery. This includes the development of methodological strategies that employ the UAV. This development has required a shift in our traditional methodological perspectives about sampling frameworks and data gathering. For example, the UAV is currently being used to examine biogeographic aspects of squarrose knapweed (Centaurea virgata Lam. ssp. squarrosa Gugl.) at several sites in Utah. Original research protocols envisioned the use of traditional transects to determine weed densities along invasion corridors. However, it became apparent that such transects were unnecessary because the populations of weeds could be mapped directly from the UAV photography. The population plant density could be censused directly from the photography without resorting to sampling.

\section{LITERATURE CITED}

Carneggie, D. M., and J. N. Reppert. 1969. Large-scale 70-mm aerial color photography. Photogrammetric Engineering 35:249-257.

Everitt, J. H., D. E. Escobar, J. R. Noriega, M. R. Davis, and I. Cavazos. 1997. A digital imaging system and its application to natural resource management. In: M. Bauer, W. Befort, R. Pol, Ir. Coppin, and B. Huberty [eds.], Proceedings of the 1st North American Symposium on Small Format Aerial Photography; 14-17 October 1997; Cloquet, MN. Bethesda, MD: American Society of Photogrammetry and Remote Sensing. p 123-135.

Hunt, E. R., J. H. Everitt, J. C. Ritchie, M. S. Moran, D. T. Booth, and G. L. Anderson. 2003. Applications and research using remote sensing for rangeland management. Photogrammetric Engineering and Remote Sensing 69:675-693.

NyouIST, J. E. 1997. Unmanned aerial vehicles that even geoscience departments can afford. Geotimes 42:20-23.

Quilter, M. C., And V. J. Anderson. 2001. A proposed method for determining shrub utilization using (LA/LS) imagery. Journal of Range Management $54: 378-381$.

Walker, J., and S. L. De Vore. 1995. Low altitude large-scale reconnaissance: a method of obtaining high resolution vertical photographs for small areas. Denver, C0: National Park Service, Rocky Mountain Regional Office, Interagency Archeological Services, Division of Partnerships and Outreach. 161 p. 